This item was submitted to Loughborough's Research Repository by the author.

Items in Figshare are protected by copyright, with all rights reserved, unless otherwise indicated.

\title{
Radio frequency IDentification miniature interrogator antenna sprayed over an in-vehicle chassis
}

PLEASE CITE THE PUBLISHED VERSION

http://digital-library.theiet.org/content/journals/iet-map

PUBLISHER

(C) Institution of Engineering and Technology (IET)

VERSION

AM (Accepted Manuscript)

LICENCE

CC BY-NC-ND 4.0

\section{REPOSITORY RECORD}

Zuazola, I.J. Garcia, A. Sharma, J.C. Batchelor, I. Angulo, A. Perallos, W.G. Whittow, J.M.H. Elmirghani, and R. Langley. 2019. "Radio Frequency Identification Miniature Interrogator Antenna Sprayed over an In-vehicle Chassis". figshare. https://hdl.handle.net/2134/11522. 
This item was submitted to Loughborough's Institutional Repository (https://dspace.lboro.ac.uk/) by the author and is made available under the following Creative Commons Licence conditions.

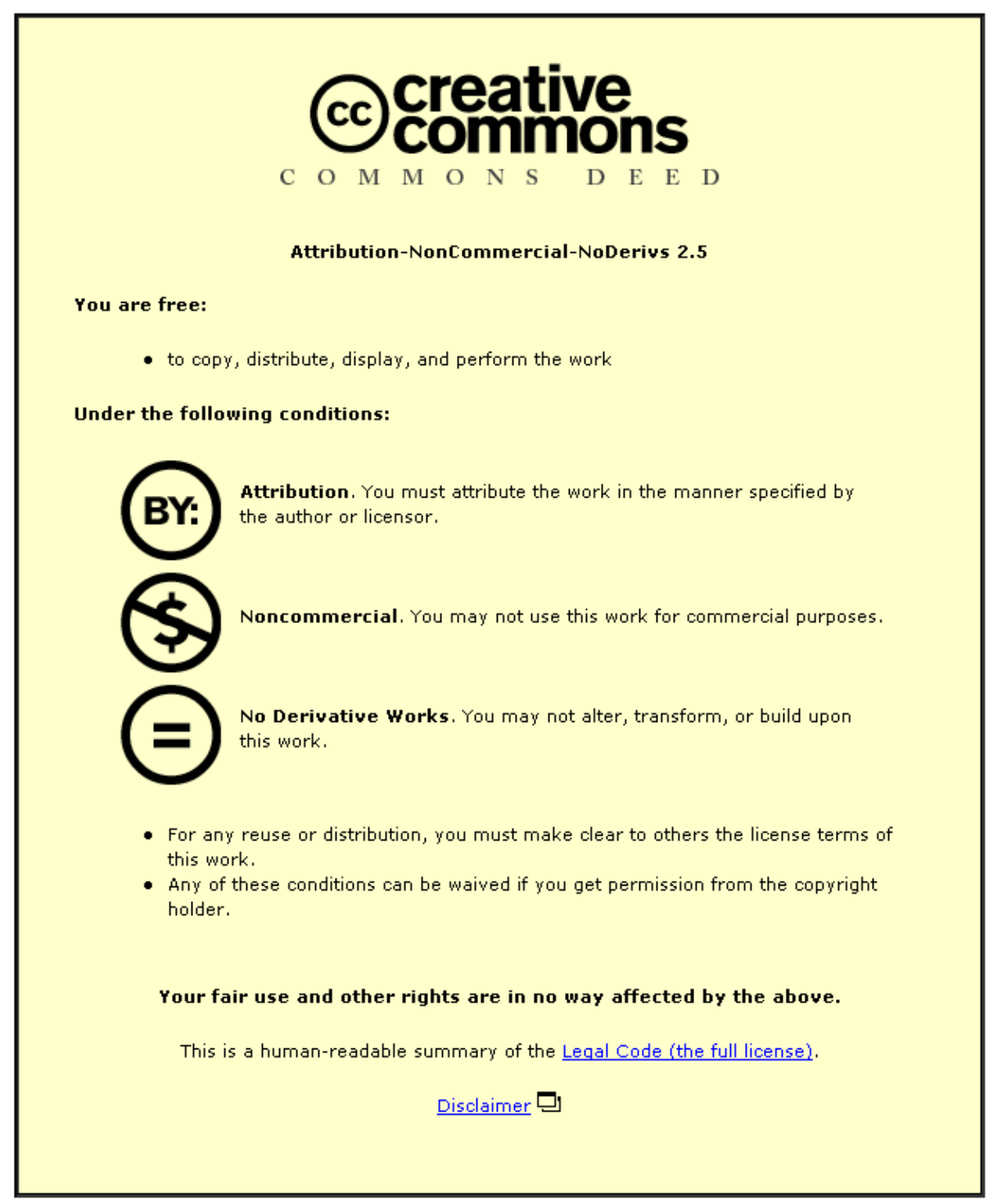

For the full text of this licence, please go to: http://creativecommons.org/licenses/by-nc-nd/2.5/ 
Final author version. This paper has been published in IET Microwaves, Antennas \& Propagation. Volume 6, Issue 15. Pp $1674-1680.2012$

\title{
AN RFID MINIATURE INTERROGATOR ANTENNA SPRAYED OVER AN IN-VEHICLE CHASSIS
}

\author{
I.J. Garcia Zuazola ${ }^{1,4^{*}}$, A. Sharma1 ${ }^{1}$ J.C. Batchelor ${ }^{2}$, I. Angulo ${ }^{1}$, A. Perallos ${ }^{1}$, \\ W.G. Whittow ${ }^{3}$, J.M.H. Elmirghani ${ }^{4}$ and R. Langley ${ }^{5}$ \\ ${ }^{1}$ Deusto Institute of Technology $\quad{ }^{2}$ Department of Electronics ${ }^{4}$ School of Electronic and \\ DeustoTech, University of Deusto, University of Kent, Electrical Engineering, \\ Avenida de las Universidades 24, Canterbury, Kent, University of Leeds, \\ 48007 - Bilbao, Spain CT2 7NT, UK Leeds, LS2 9JT, UK \\ ${ }^{3}$ School of Electronic, $\quad{ }^{5}$ Electronic and Electrical Engineering \\ Electrical and Systems Engineering The University of Sheffield \\ Loughborough University, Western Bank, Sheffield, S10 2TN, U.K
} Loughborough, Leicestershire, LE11 3TU

*Email: igarcia@theiet.org

\begin{abstract}
:
Among the different assets tracking solutions Radio Frequency IDentification RFID is a promising technology for in-car communications due to its relatively low cost deployment and real time monitoring and processes. In this paper, a hidden, miniature, narrow band antenna of dimensions $0.18 \lambda \times 0.20 \lambda \times 0.005 \lambda$ is presented which is easy to manufacture using conductive paint sprayed over a car body. The design relies on a resonator, a negative image of the radiator for improved efficiency when in close proximity to ground planes and is suited for use in radio frequency identification networks using the unlicensed RFID band (865.6867.6 $\mathrm{MHz}$ ) is described. The term miniature comes from the fact that the antenna is physically small given the low proximity and insensitivity to the ground plane which facilitates a possible coating layer over the antenna for hidden applications.
\end{abstract}

\section{$1 \quad$ Introduction}

Radio Frequency IDentification RFID technology has gained huge interest globally due to the diversification of the range of emerging applications and low power, low cost design. The 
Final author version. This paper has been published in IET Microwaves, Antennas \& Propagation. Volume 6, Issue 15. Pp $1674-1680.2012$

deployment of the widely employed UHF RFID (UHFID) wireless technology will provide real-time identification, management, and assets tracking in vehicles using web based networks for anytime/anywhere article surveillance (i.e.: location and checkout). The low power low cost is achieved using passive (uses no battery) RFID transponders (TPDRs).

Among applications, pharmaceutical item tracking inside vehicles is required to support the needs of Pharmaceutical corporations to pilot their supply chains activities [1].

The two most common implementations of RFID systems are based on the interrogator motion ability. Fixed RFID is utilised since the interrogator inside a vehicle is immobile. Although the vehicle might be moving, antennas placed inside vehicles do not in principle suffer from Doppler Shift [2]. RFID backscattered modulated signals technology is used for the interrogation of transponders [3].

To meet the demands outlined above, a miniature low-cost antenna for use in hidden applications will be introduced in this paper. The antenna radiator will be directly sprayed over the inside car body with acceptable performance for a hidden application. The design is suited for use in radio frequency identification networks using the unlicensed RFID subband b2 (865.6-867.6 MHz) of the ETSI standard [4]. The integration and interaction of the antenna with the car body will be analysed.

\section{$2 \quad$ Antenna Structure}

The structure of the printed Planar Inverted-F Antenna (printed-PIFA) introduced in this paper is shown in Fig.1. To realise the miniature narrow band antenna, a conductive paint, 
Final author version. This paper has been published in IET Microwaves, Antennas \& Propagation. Volume 6, Issue 15. Pp $1674-1680.2012$

conducts electricity with a resistivity, Res $<0.015 \mathrm{ohms} / \mathrm{sq}$. (measured at density-functional theory, DFT $=50$ microns) [5], is sprayed over a painted car body with a manufacturer typically employed total paint thickness [6] of $125 \mu \mathrm{m}\left(3.61 \mathrm{e}^{-4} \lambda\right)$; the final prototype had a total thickness of $2 \mathrm{~mm}(0.005 \lambda)$, Fig. 1 . The dielectric constant of a typical coated car (paint) is $\varepsilon r 6.5$ [7], and is corroborated by measurements. The principal dimensions are given in Fig.2. The measured permittivity, Fig. 3, of the vehicle composite and the paint coating, using a sounding probe method [8] that employs an Agilent 85070E Dielectric Probe, was 6.31 and 6.53 (back-side of the car chassis panel) respectively; although the antenna was finally sprayed over the composite, this is not of relevant difference for the antenna to be prototyped on the paint coating. A small difference in permittivity was found for the front-side (polished paint) and back-side (unpolished paint) of the car chassis; this is a lower 1.73 and 1.68 respectively for the composite and the coating layers.

The approximate resonant frequency $\left(f_{r}\right)$ of a PIFA with a certain size can be determined from [9]. Typically, a microstrip PIFA antenna performing at the centre band of $866.6 \mathrm{MHz}(2$ $\mathrm{MHz}$ bandwidth) and a $125 \mu \mathrm{m}$ paint substrate would require the size of $0.25 \lambda \times 0.36 \lambda$ in contrast to the $0.18 \lambda \times 0.20 \lambda$ (including the resonator $\mathrm{A}$, a negative image of the radiator $\mathrm{B}$ ) using the proposed printed-PIFA.

PIFA designs based on a large ground plane usually lead to bandwidths that are very narrow (less than $8 \%$ ) [10]. The bandwidth is further reduced if the separation between the top radiating and bottom layers is small (about $0.5-0.9 \%$ per $0.018 \lambda$, usually for antennas less than $0.168 \lambda$ in height). Using Zeland IE3D (CAD) software it can be established that an initial design printed-PIFA operating from $864.8-867.7 \mathrm{MHz}$ has a total fractional bandwidth of 
Final author version. This paper has been published in IET Microwaves, Antennas \& Propagation. Volume 6, Issue 15. Pp $1674-1680.2012$

$0.32 \%$ for $\mathrm{S} 11$ equal to $-10 \mathrm{~dB}$. This is a very narrow bandwidth (only a narrow band is required in RFID applications) which is welcome as a contribution to the rejection of the influence of nearby radios.

The printed-PIFA introduced here has a striped top patch to create a meandering current path and reduce the overall length of the structure. The feed is at the central patch of the antenna design to offer a convenient interface to potential transceivers located at the back of the car enclosure. A flexible coaxial cable terminated by an SMA connector was however used to feed the antenna in the measurements. The required elements of the strip pattern in the upper part of the printed-PIFA and the extended image radiator A, which was required to achieve the desired bandwidth using a coat (paint), is shown in Fig. 2. The antenna is implemented first by spraying a conductive ink to realise the resonator A over the coated car body (existing layer), h, Fig. 1, second, re-coating A using typical car paint (additional layer), h', Fig. 1, to provide a non-conductive separation layer between A and B, finally, spraying conductive ink to realise the antenna radiator B; the dimensions are given in Figs. 1 and 2.

\section{$2.1 \quad$ The principal radiating elements}

The initially striped printed-PIFA radiator B of $19.43 \times 33.8 \times 0.125 \mathrm{~mm}^{3}(0.056 \lambda, 0.097 \lambda$ and $3.61 \mathrm{e}^{-4} \lambda$ ) was designed at $825.8 \mathrm{MHz}$ offering a fractional bandwidth of $0.22 \%$ at $-29 \mathrm{~dB}$. This however, was seen as a "match load" since $-40 \mathrm{dBi}$ gain (a near zero radiation efficiency) was observed. Antennas when in very close proximity to a ground plane (PEC) suffer from severe lack in radiation efficiency [11]. This is due to the "mirroring effect" reverse image current cancellations caused in the PEC and counteracting the impedance mismatch (typically a poor return loss) of the antenna. EBGs (an in-phase reflection coefficient) can improve the 
Final author version. This paper has been published in IET Microwaves, Antennas \& Propagation. Volume 6, Issue 15. Pp $1674-1680.2012$

radiation efficiency; however, current inevitable thickness of constructed EBGs, 2mm [12] and the additional required separation between the radiator and the EBG in order to perform, an air-gap of $\sim 3 \mathrm{~mm}[12]$, increases the final width design of prospect antenna structures using this technology.

Observation on predictions showed that when the printed-PIFA radiator B is $2 \mathrm{~mm}(0.005 \lambda)$ away from the ground plane, a $-22.5 \mathrm{dBi}$ gain (a $2.25 \%$ radiation efficiency) was achieved; this is a 1.7/1 improvement. However, the reflection coefficient (S11) of the antenna was constrained by a ratio of $0.012 / 1$. This is attributed to the improved radiating performance of the printed-PIFA and the no longer "match load" behaviour. Adding a resonator A, a negative image of the radiator B with an extended plane of 2.07/1 and 3.35/1 respectively for length, $l$, and width, $w$, of the plane, is an effective plane for favouring fringing edges currents of the radiator $\mathrm{B}$ by impinging them to a resonator $\mathrm{A}$; it was found that when this plate is $65.33 \mathrm{~mm}$ $\mathrm{x} 70.04 \mathrm{~mm} 0.18 \lambda \times 0.20 \lambda$, best gain and impedance matching is achieved (reducing $l$, greater operational frequency; increasing $w$, deeper $\mathrm{S} 11$ ). A $2 \mathrm{dBi}$ gain (a $51 \%$ radiation efficiency) is achieved; this is a 24.5/1 improvement as compared to the printed-PIFA without the resonator A. Simulated results for different $l$ and $w$ dimensions are given in Table 1. Adjusting equally percentages for $l$ and $w$, lower and upper shifts of the central resonance frequency is achieved with intervals sufficient to encompass worldwide RFID bands (a required total band of $78 \mathrm{MHz}$ and a typically used sub-channel band of $2 \mathrm{MHz}$ ). Among the worldwide RFID frequency bands are 902-928MHz (FCC; NA, SA), 865.6-867.6MHz (ETSI; EU), 865867MHz (MCIT; India) to 866-870MHz and 940-943MHz (China) [13]. 
Final author version. This paper has been published in IET Microwaves, Antennas \& Propagation. Volume 6, Issue 15. Pp $1674-1680.2012$

The structure was modelled and the current density was observed. A simulated RF current distribution, Fig. 4, show the contour field difference for the printed-PIFA radiator B with and without the resonator A. It can be seen that currents originating in the ground plane (immediately underneath the radiator B) in Fig. 4a are no longer seen in Fig. 4b; this is perceived as a positive contribution in the $180^{\circ}$ reflection phase cancellation encountered by a normally incident plane-wave (cancelation of the impinging currents) at a ground plane. The resonator $\mathrm{A}$ has a significant role; compared the printed-PIFA without $\mathrm{A}$, the antenna with $\mathrm{A}$ presents an improved 2/1 and 1.7/1 respectively for the gain and efficiency. To achieve the same gain of $2 \mathrm{dBi}$ without the resonator $\mathrm{A}$, the printed-PIFA has to be $0.07 \lambda$ away from the ground plane, $\mathrm{C}$.

The antenna radiator B is now described. PIFA antennas printed on a substrate can contribute to simplified designs with improved bandwidth [14]. Introducing strips to form the top patch creates a meandering current path that reduced the overall length of the antenna [14]. Strips were used to design the antenna radiator, Fig. 2. Element a, showing a $U$ shape geometry has the length required for the resonance at $866.6 \mathrm{MHz}$. The inclusion of element $\mathrm{b}$ facilitates the antenna feeding by providing a right interface between element $b$ and element $e$. The feed is at near the central patch of the antenna for via through connection. Element $\mathrm{c}$ and $\mathrm{d}$ forms a capacitive coupling which adjusts for impedance resonance to be centred with a fine range. In addition, the gap provided by the elements reduces the electrical length of the PIFA by creating a meandering path for the radiator. Element e adjusts the impedance resonance of the antenna for an increased/reduced bandwidth of the PIFA by a fine range of $0.17 \mathrm{MHz}$ while leaving the operational frequency unchanged. This beneficially rejects nearby frequencies. 
Final author version. This paper has been published in IET Microwaves, Antennas \& Propagation. Volume 6, Issue 15. Pp $1674-1680.2012$

The radiator $\mathrm{B}$ is not connected to the ground plane $\mathrm{C}$ which has the effect of increasing the gain by $2 \mathrm{dBi}$.

The final RF current distribution of the optimally tuned antenna with the dimensions given in Fig. 2 is depicted in Fig. 4b.

The term 'miniature' is applied to this printed-PIFA as the gain is $2 \mathrm{dBi}$ for a compact size of $65.33 \times 70.04 \times 2 \mathrm{~mm}^{3}$ where the electrical dimensions in terms of wavelength are respectively $0.18 \lambda \times 0.20 \lambda \times 0.005 \lambda$. The antenna is therefore considered as miniature as it provides high efficiency in a compact volume.

The constructed printed-PIFA shown in Fig.1 with the dimensions of Fig.2 was generated by spraying a conductive ink using negative masks with a scale $1 / 1$ fabricated in polyurethane sticker. To account for any possible variations in the manufacturing process, Table 2 provides with the expected centre frequencies, total bandwidth, return loss, including the upper and lower roll-offs values, and the gain of the antenna for trivial thicknesses of $h$ and $h^{\prime}$ paint coating layers. Whereas greater gains are observed for larger thicknesses of $\mathrm{h}$ till a maximum value of $h=3.2$, this is compromised with bandwidth. For the case of $h^{\prime}$, maximum gains are observed for $\mathrm{h}^{\prime}=3.45$.

\section{Experimental set-up}

For the simulated in-car system set-up, the cargo area of a Ford Transit van modelled as a complete shield room of $1.8 \times 2.6 \times 1.4 \mathrm{~m}^{3}$ for the carriage of goods was used; Fig. 5 shows a high-level block diagram for the in-car system. The printed-PIFA is located in the middle of 
Final author version. This paper has been published in IET Microwaves, Antennas \& Propagation. Volume 6, Issue 15. Pp $1674-1680.2012$

the ceiling of the vehicle; as preliminary predictions indicated to be the preferred location to ensure optimal radio propagation illumination inside the vehicle. The printed-PIFA was used as a transceiver (transmit and receive) and had a gain of $2 \mathrm{dBi}$. Commercially available tags [15] (identify parcels containing medicines) were assumed to receive and backscatter power inside the vehicle; they retrieve the required power to make them active (integrated chip). In general, passive (no battery powered) RFID tags use the received power of an antenna interrogator to power their integrated chip and backscatter (reflection) the power to back transmit to the interrogator. The maximum receive sensitivity of a typical transceiver is $-65 \mathrm{dBm}$ assuming a full transmit power with a 1.5:1 VSWR antenna [16], and no maximum sensitivity enforcement is probable. Because the employed antenna corresponds to a $1.92: 1$ VSWR it is reasonable to expect a receiver sensitivity of $-64.72 \mathrm{dBm}$. The transmission is given by a maximum output power of $30 \mathrm{dBm}(1 \mathrm{~W})$ for the subband b2 $(8.656-8.676 \mathrm{GHz})$. The employed antenna VSWR response, introduced in section 4, corresponds to a mismatch loss of $0.458 \mathrm{~dB}$. Maximum allowed transmit power of RFID is dictated by ETSI to $1 \mathrm{~W}$ Effective Radiated Power (ERP) [4]; this is, a 1.6W EIRP. Because the transceiver emits an output power up to $30 \mathrm{dBm}(1 \mathrm{~W})$, simulated results of Fig. 5 anticipates that a non-greater than a $2 \mathrm{dBi}$ antenna can be utilised in this application to meet the regulation criteria; using higher gain antennas would require a reduced input power to the antenna and effectively lead to large designs; a $2 \mathrm{dBi}$ antenna design is therefore perceived as a size optimized antenna for the application.

\section{$4 \quad$ Antenna measurements}


Final author version. This paper has been published in IET Microwaves, Antennas \& Propagation. Volume 6, Issue 15. Pp 1674 - 1680. 2012

Figure 6 shows a comparison of the measured and simulated return loss of the narrowband printed-PIFA antenna. Construction tolerances, mainly given by the voltage currents raised at the junction between the feed and the antenna structure, meant there was some difference between the simulated and measured S11 for the printed-PIFA. The measured results present a return loss of $-10 \mathrm{~dB}$ for the entire bandwidth of $266 \mathrm{MHz}$. Additionally, the narrow band antenna presents a flat response of about $-5 \mathrm{~dB}$ for the upper and lower frequencies. The return loss of the antenna over a larger ground plane, D, of dimensions $510 \times 800 \times 0.75 \mathrm{~mm}^{3}$ showed no mismatch or de-tuning of the input impedance response of the antenna. The antenna can then be considered insensitive to larger ground planes and therefore platform tolerant.

The radiation patterns were measured in an anechoic chamber in polar patterns for the frequency band of interest. Figure 7 shows the antenna radiation patterns covered $360^{\circ}$ for the azimuth H-plane. This $360^{\circ}$ antenna characteristic can be useful for in-vehicle applications [5] where the pattern projects in all the orientations inside the vehicle. Figure 8 shows a simulated antenna radiating efficiency of $46 \%$, an antenna gain of $2 \mathrm{dBi}$ and associated high directivity (for the extremely low separation, $2 \mathrm{~mm}$, between the radiator and the ground plane of the antenna) at a calculated VSWR 1.92:1. The results indicate that this antenna is potentially adequate for in-vehicle hidden applications where the antenna radiator is sprayed over the coating of a vehicle body. In addition, other applications (e.g. embedded in coated metals) such as kitchen appliances are also envisaged. The antenna (using the paint substrate) gain was measured $4 \mathrm{dBi}$ down as compared to the simulated and was given by manufacturing tolerances; the substrate thickness was smaller than that of the initial design. Future developments are encouraged to retune the load of the antenna to match the chip of an RFID 
Final author version. This paper has been published in IET Microwaves, Antennas \& Propagation. Volume 6, Issue 15. Pp $1674-1680.2012$

tag; this can bring the antenna to applications such as the use in bikes, fire extinguishers, vehicle's plate registration numbers, vehicles and heavy machinery.

This antenna can easily be integrated in vehicles, such as cars, and other articulated vehicles and in applications where large ground planes are encountered. The addition of the additional ground plane, $\mathrm{D}$, does not significantly alter the bandwidth and return loss of the antenna, Fig.6; any possible weak resonance can be expected due to the effect of the enclosure. However, the antenna enclosure (the car body) could act as an antenna resonator (an excited cavity), this is subsequently analyzed.

Figures 9 and 10 show respectively the corresponding radiation patterns of the printed-PIFA in the far-field with and without the extra ground plane, D, and the pattern seen outside the fuselage of the vehicle (when the printed-PIFA is located inside the vehicle). This can predict surface waves occurring at the enclosure resonance which might have significant effect to the properties (i.e.: change the VSWR performance due to originated reflections) of the antenna. Measured radiation patterns present a printed-PIFA antenna covering $360^{\circ}$ for the azimuth $\mathrm{H}$ plane and thus propagating in all the orientations inside the vehicle, Fig. 9. The simulated gain seen outside the fuselage of the car body (printed-PIFA antenna inside the vehicle), Fig. 10 , was about $20 \mathrm{dBi}$ lower than that compared to the printed-PIFA antenna (without the body). This gives confidence that radio propagation is encountered outside the vehicle and ensures the possibility of using higher powers inside the vehicle (up to 4W ERP indoors); this is translated to an increase of $3.16 \mathrm{dBm}$ in the actual power at the interrogator.

\subsection{Signal strength and Propagation coverage}


Final author version. This paper has been published in IET Microwaves, Antennas \& Propagation. Volume 6, Issue 15. Pp 1674 - 1680. 2012

In principle, radiation propagation inside vehicles is favoured for seizing RF energy with minimal loss, however, because the enclosure is not a perfect shield, surface losses due to the metal imperfection are originated. As antennas do not radiate power uniformly in all directions, the signal strength inside the car body (interrogation zone) is therefore analysed. IE3D software using a full wave Finite Difference Frequency Domain (FDFD) is used for the simulation. Although the ray tracing technique [17] is typically utilised to analyse complex environments, FDFD is more precise for this application since the enclosure (car body) can account for a significant impact upon the antenna performance (i.e.: matching) [18]. In addition, because the pattern (radiator) of the designed antenna is directly sprayed over a car body, the enclosure might actually perform as an extra added ground plane (the plane below the antenna radiator) and as a capacity-coupling resonator (the plane above the antenna radiator); this might lead to radiation propagation in a far-field outside the car body. A series of simulations were taken to establish suitable location for the antenna inside the vehicle; it was found that the best location for the antenna was in the middle of the ceiling of the car. The simulated power strength at the edges of the car body (inside) is depicted in Fig. 5 showing $\sim 22 \mathrm{dBm}$ in the worst case. In addition, performed simulations established that the amount of energy being radiated out of the enclosure has fall $20 \mathrm{~dB}$ with respect to the antenna without enclosure; this is an expected value since the enclosure is expected to prevent some of the power being radiated out of the car body. It is also expected in this application multipath contributions (nulls due to the out-of-phase multipath interference and positive strong signals [19] ) counting towards the available power strength; the received power strength for likely tag locations inside the vehicle is given in Table 3; it can be seen focuses of strong signal power for the tags. The analysis for the power predictions used a deterministic approach in near field; the far field cannot be measured inside the vehicle. Far field measurements were 
Final author version. This paper has been published in IET Microwaves, Antennas \& Propagation. Volume 6, Issue 15. Pp $1674-1680.2012$

used to analyze powers leaving the fuselage of the car. It can be observed that when the tags are closer to the edges of the vehicle chassis the more the radiating power strength is achieved.

Assuming that the backscattered power of the tag is equal to that it received and has a symmetric path loss in the downlink and uplink, the calculated received power at the interrogator for the $1.3 \mathrm{~m}$ range is $-60 \mathrm{dBm}$; this is $30 \mathrm{dBm}-(2 \times 45 \mathrm{dBm})=-60 \mathrm{dBm}$ and is a suitable power to be understood by the receiver sensitivity of $-64.72 \mathrm{dBm}$. There is no need to increase the amplification of the integrated LNA since these guarantees for a $4.72 \mathrm{dBm}$ increase in the receiver sensitivity if improvement of the interrogation zone was desired.

\section{$5 \quad$ Conclusion}

A low cost miniature narrowband PIFA antenna for straightforward integration inside vehicles and hidden applications has been presented formed by using a conductive paint sprayed over a car body with good return loss, gain and $360^{\circ}$ radiation patters in the azimuth $\mathrm{H}$-plane.

Measured and simulated results indicate that this antenna works satisfactorily in the unlicensed UHF RFID (UHFID) band (865.6-867.6 MHz) and can cover worldwide RFID frequency bands, such as the $902-928 \mathrm{MHz}$ (FCC; NA, SA), 865.6-867.6MHz (ETSI; EU), $865-867 \mathrm{MHz}$ (MCIT; India) to $866-870 \mathrm{MHz}$ and $940-943 \mathrm{MHz}$ (China) [13], with potentially non-resonances in the nearby lower and upper frequency bands; this provides immunity to adjacent transmitting RF signals in the vicinity. A variant antenna design capable of achieving multiband response using switching technology is to be considered for future research. 
Final author version. This paper has been published in IET Microwaves, Antennas \& Propagation. Volume 6, Issue 15. Pp $1674-1680.2012$

The integration and interaction of the antenna inside a car body was analysed, a series of simulations and corroborated measurements characterised the in-car channel and evaluated the performance of a typical RFID interrogation zone in this setting. Results indicate that the design proves to be proficient for in-vehicle applications. The $360^{\circ}$ radiation pattern of the proposed interrogator antenna in the azimuth H-plane, guarantees coverage in-car and simulated RF signal powers of $20 \mathrm{dBm}$ average. The distributed powers inside the vehicle provided with an efficient communication to likely distributed tags. In addition, a study of measurements of currently unknown models describing the radio channel for a new RFID in real environment applications is needed to overcome the lack of propagation models (statistical-realistic approach) for this application and it is intended that the knowledge gained from this study may be used to characterise such channels, concluding that RFID is a very suitable and promising technology for the interrogation zone able to provide high read rates. LOS transmission can improve the system read rate meaning that potentially directional antennas such as patch arrays and beam steered arrays, could improve the overall system performance. Multiple antenna schemes [20] compared to single antenna settings provide a closer received signal recovery to a transmitted and higher data rates.

The use of EBG structures to shielding the enclosure of vehicles is to be considered in future research. The use of these periodic structures can contribute to higher powers in-car; ideally (this rather occurs in practise) any possible power inside a perfectly design EBG dice will never die [21].

\section{Acknowledgment}


Final author version. This paper has been published in IET Microwaves, Antennas \& Propagation. Volume 6, Issue 15. Pp $1674-1680.2012$

This work has been part-funded by the European Union. Many thanks to Igor Minaev (ETSI), Paolo Galdini (Agilent Technologies), Michael Klein (ThingMagic) and Eva Siuda (Spraylat) for the technical support. Thanks to Paco Puerto (Pegatinalia) for the preparation of the masks required for the antenna fabrication. Thanks also to Diego Perez (University of Alcala) for the anechoic chamber measurements.

\section{$7 \quad$ References}

[1] Lauren R. Hartman, Packaging Digest edition, 1/1/2006.

[2] I.J. García Zuazola, J.M.H. Elmirghani, and J.C. Batchelor, "High-speed ultra-wide band in-car wireless channel measurements"; Communications, IET, Volume 3, Issue 7, July 2009 Page(s):1115 - 1123

[3] Mervi Hirvonen, Kaarle Jaakkola, Pekka Pursula, and Jussi Säily, "Dual-Band Platform Tolerant Antennas for Radio-Frequency Identification", IEEE Transactions on Antennas and propagation, Vol. 54, No. 9, pp. 2632-2637, Sept. 2006.

[4] http://www.etsi.org/website/document/plugtestshistory/2008rfid/tr_10264402v010101p.pdf

[5] 599-B3755 Copper Conductive Coating from Spraylat, available [online] at http://www.spraylat.com

[6] http://www.ehow.com/how_5804374_measure-paint-thickness.html

[7] https://www.clippercontrols.com/pages/dielectric-constant-values\#P

[8] Basics of Measuring the Dielectric Properties of Materials, Application Note, Agilent Technologies, June 26, 2006, available [online] at cp.literature.agilent.com/litweb/pdf/5989-2589EN.pdf

[9] Young-hun Lee, Won-hyun Kwon, "Dual-band PIFA design for mobile phones using H-type slits," 2004 USNC/URSI, National Radio Science Meeting, 20-25 June 2004, Monterey, California.

[10]I.J. García Zuazola, J.C. Batchelor, and J.M.H Elmirghani, Sectorized WIMAX Antenna for future Vehicular Communications Systems; Microwaves, Antennas \& Propagation, IET, Volume 4, Issue 2, Feb. 2010 Page(s):210 - 218.

[11] http://www.ee.olemiss.edu/atef/documents/publications/2006.04.pdf

[12] Y. Zhao, Y. Hao and C. G. Parini, "Radiation Properties of PIFA on Electromagnetic Bandgap substrates", Microwave and Optical Technology Letters, Wiley Periodicals, Volume 44, No. 1, pp. 21-24, Jan 5, 2005.

[13] Daniel M. Dobkin, "The RF in RFID: Passive UHF RFID in Practice", Elsevier Inc., ISBN: 0750682094, 2007.

[14] Kin-Lu Wong, "Planar Antennas for Wireless Communications," Wiley Series in Microwave and Optical Engineering, Wiley-Interscience, 20 December, 2002.

[15] http://www.confidex.fi/images/stories/pdf/product_datasheets/Carrier_Tough_Datasheet.pdf

[16] http://www.thingmagic.com/fixed-rfid-readers/mercury5/2-fixed-rfid-readers/2-mercury5

[17]R. Wahl, G. Wölfle, "Wave Propagation Inside and Around Vehicles in Dynamic Time Variant Scenarios", 63rd IEEE Vehicular Technology Conference (VTC-Spring), pp. 2883 - 2886, Melbourne, May 2006

[18]Y. C. Or, K. W. Leung, R. Mittra, K. V. S. Rao, "Platform Tolerant RFID Tag Antenna", The 2007 IEEE International Symposium on Antennas and Propagation, Honolulu, Hawaii, June 10-14, 2007.

[19] http://www.monitoringtimes.com/html/sensitivity.html

[20] Biagi, M., Baccarelli, E., "A simple multiple-antenna ultra wide band transceiver scheme for 4th generation WLAN", IEEE 58th Vehicular Technology Conference, Vol.3, pp.1903-1907, Orlando, Florida, USA, 2003.

[21] Yablonovitch E., "Photonic Crystals: What's in a name?", Optics \& Photonics News, vol.18, no.3, pp. 1213, March 2007. 
Final author version. This paper has been published in IET Microwaves, Antennas \& Propagation. Volume 6, Issue 15. Pp 1674 - 1680. 2012

\section{Figures}


Final author version. This paper has been published in IET Microwaves, Antennas \& Propagation. Volume 6, Issue 15. Pp 1674 - 1680. 2012

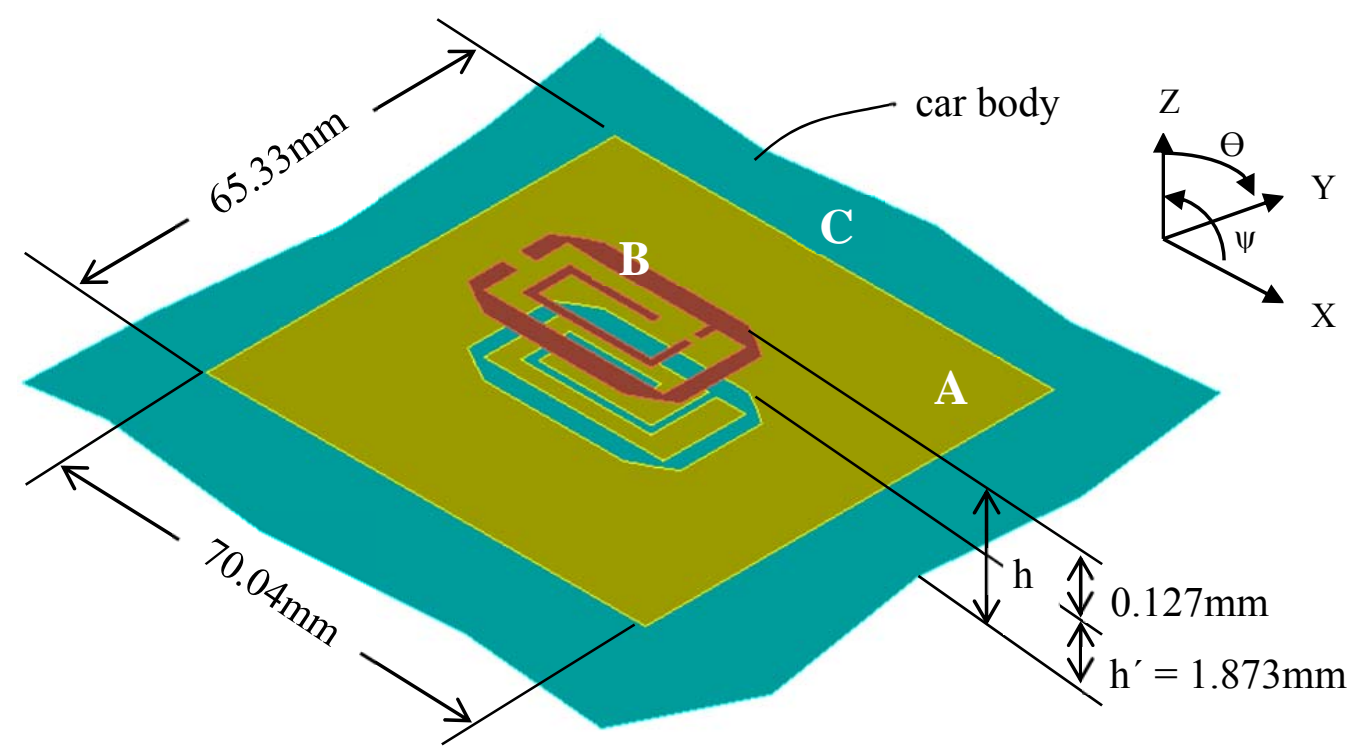

Figure 1 - The layers of the sprayed printed-PIFA over the car body

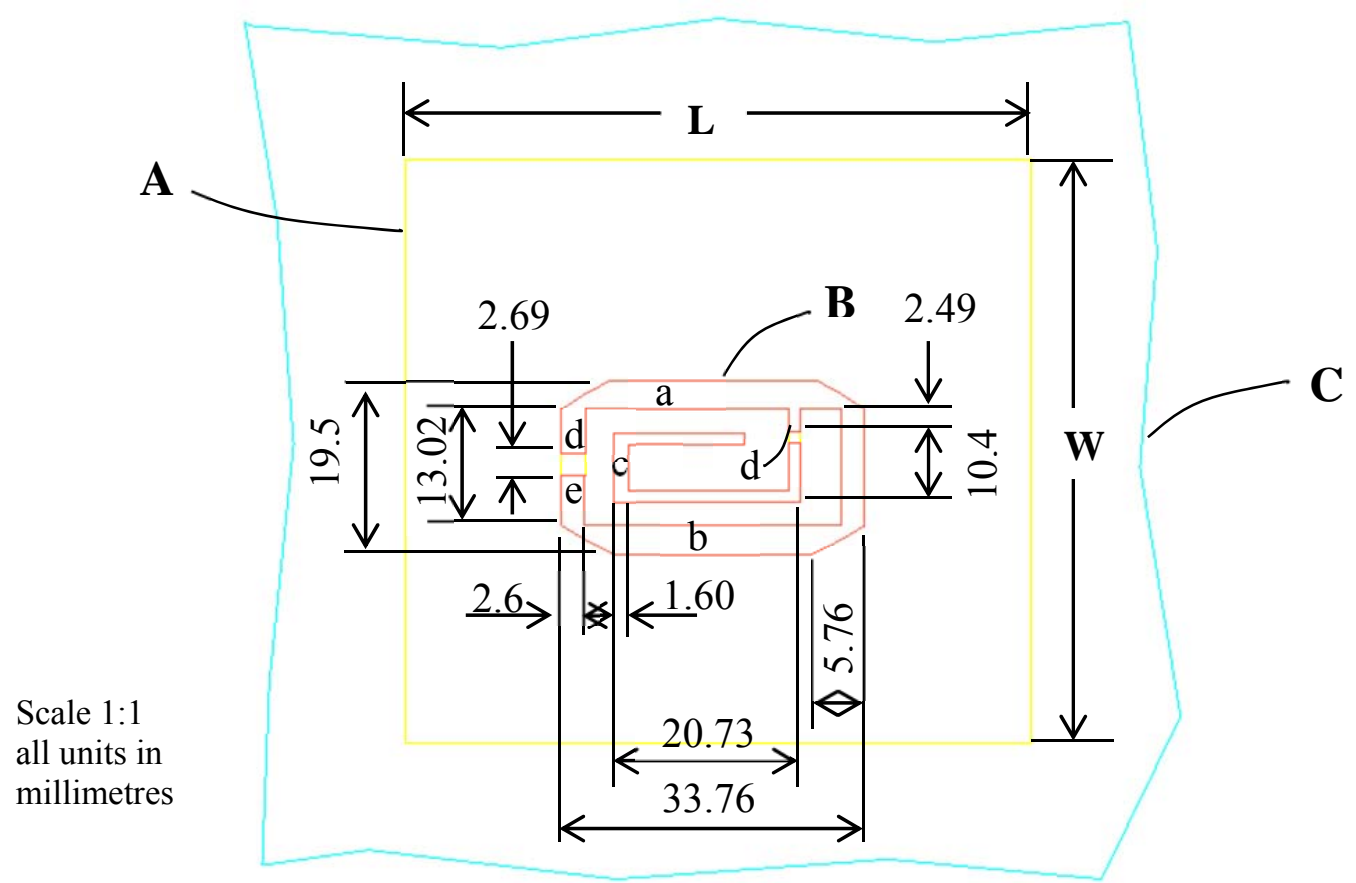

Figure 2 - The structure dimensions and elements of the printed-PIFA 
Final author version. This paper has been published in IET Microwaves, Antennas \& Propagation. Volume 6, Issue 15. Pp 1674 - 1680. 2012

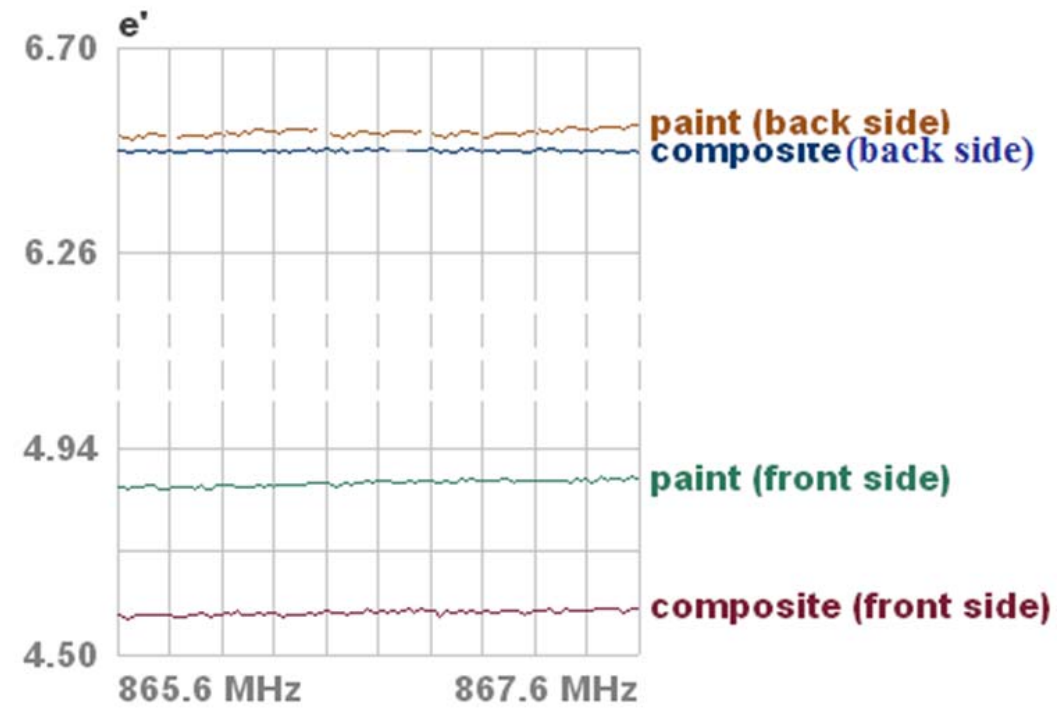

Figure 3 - Measured permittivity of the composite and paint

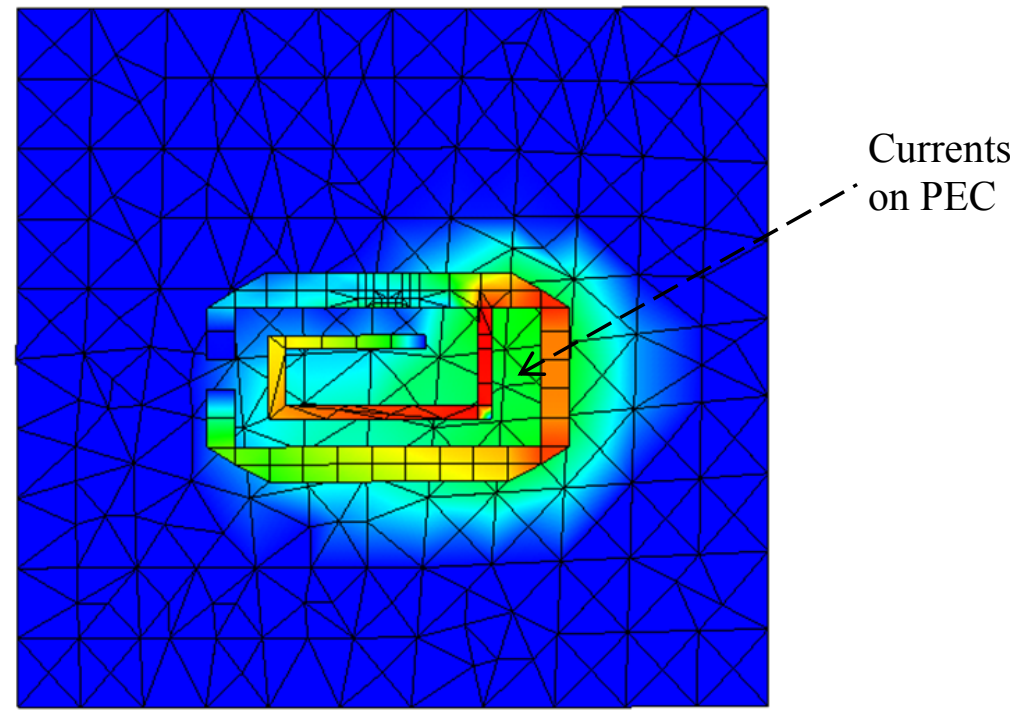

(a) 
Final author version. This paper has been published in IET Microwaves, Antennas \& Propagation. Volume 6, Issue 15. Pp $1674-1680.2012$

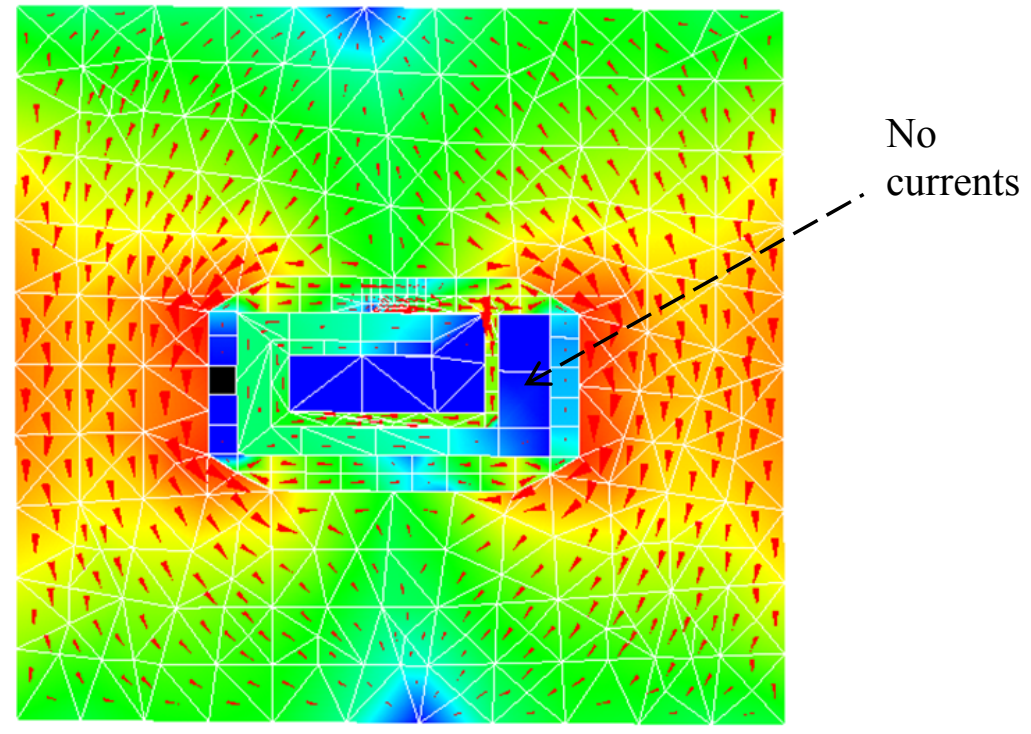

(b)

Figure 4 - RF current distribution of the radiator $B$, a) without and b) with the resonator $\mathbf{A}$

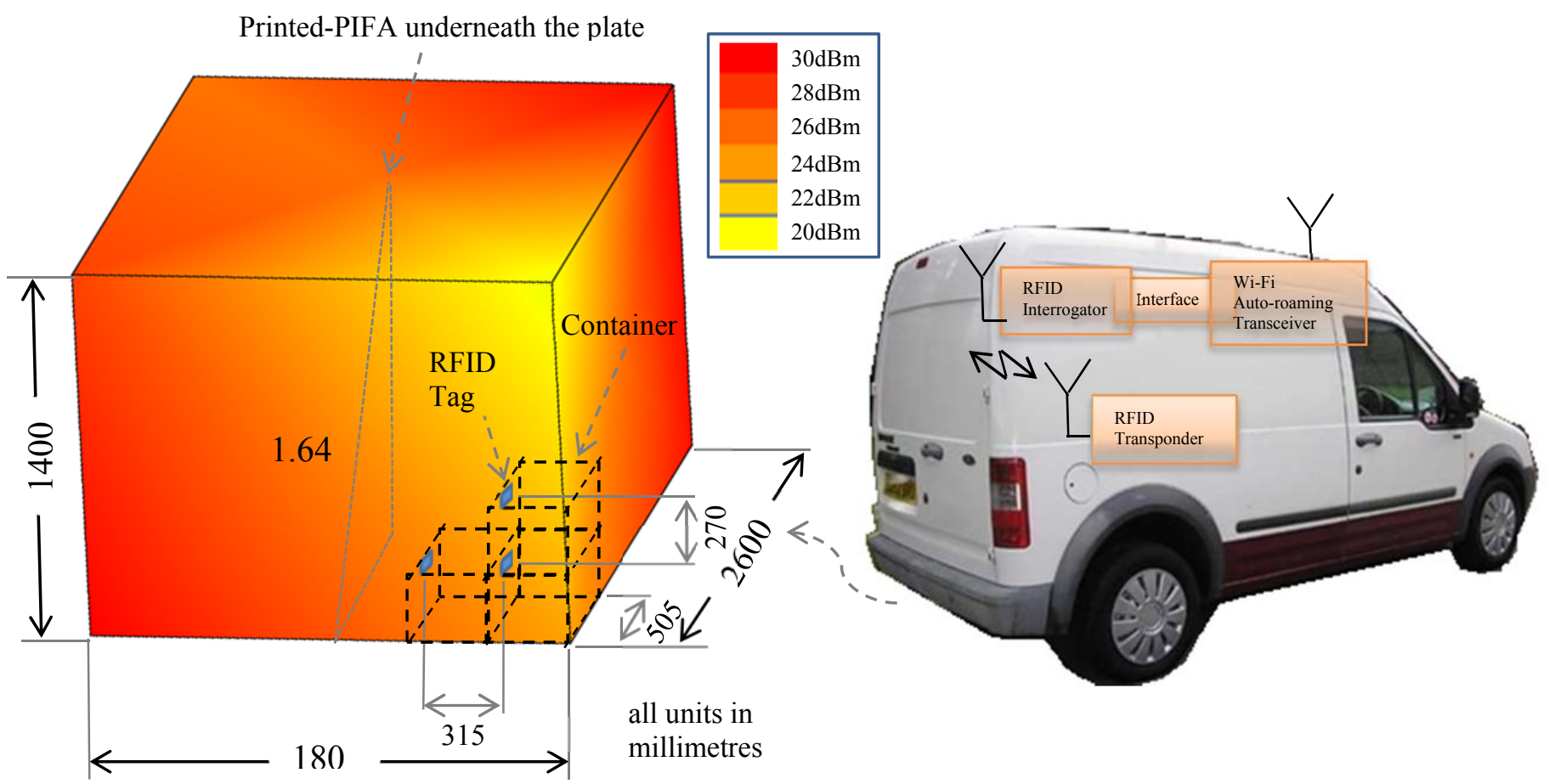

Figure 5 - The experimental set up in a typical in-car showing maximum expected simulated power strength at the edges of the car body 
Final author version. This paper has been published in IET Microwaves, Antennas \& Propagation. Volume 6, Issue 15. Pp $1674-1680.2012$

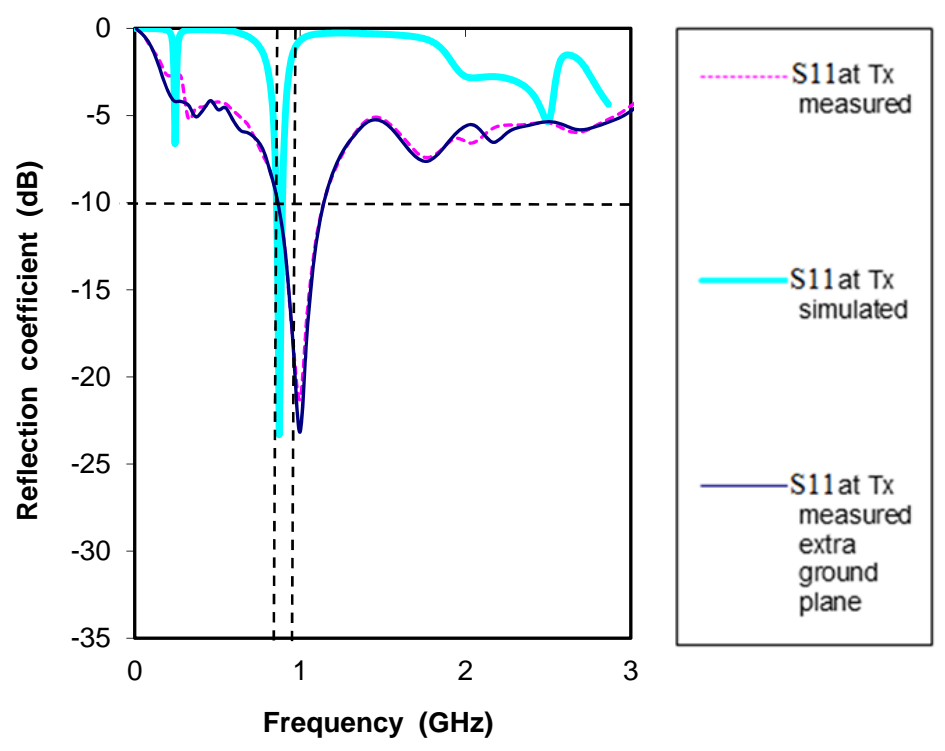

Figure 6 - Reflection coefficient (S11) of the printed-PIFA
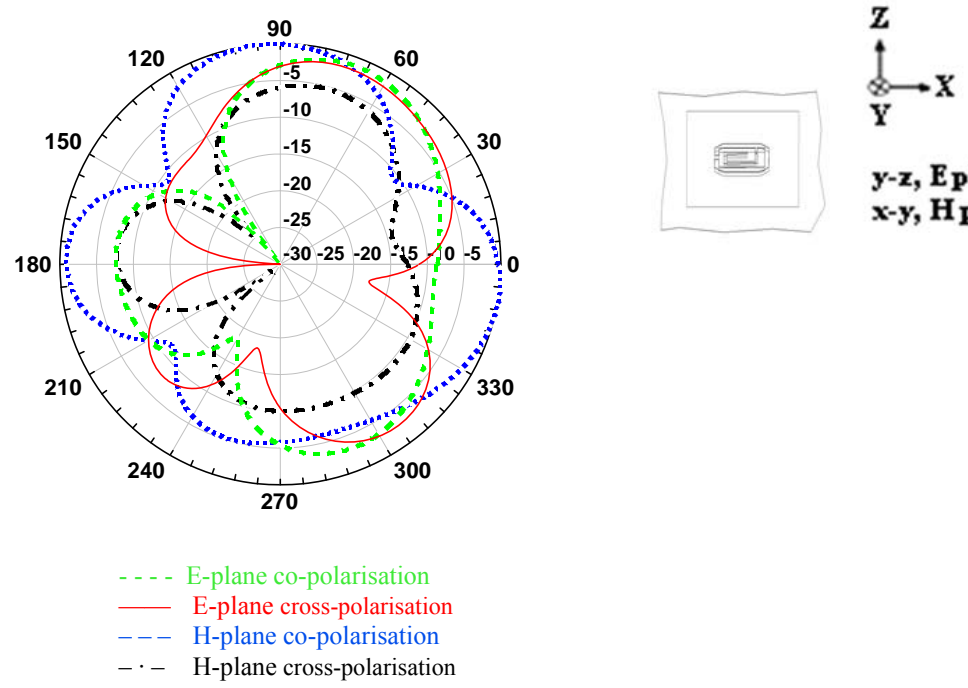

y-z, Eplane $x-y, H$ plane

Figure 7 - Radiation pattern of the printed-PIFA 
Final author version. This paper has been published in IET Microwaves, Antennas \& Propagation. Volume 6, Issue 15. Pp 1674 - 1680. 2012

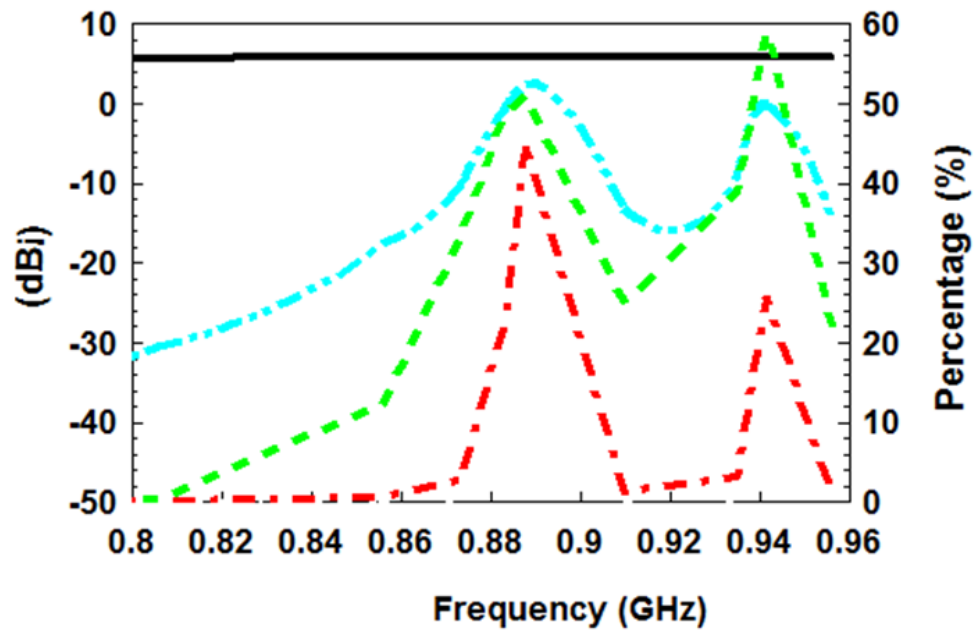

Figure 8 - Efficiency, directivity and gain of the antenna
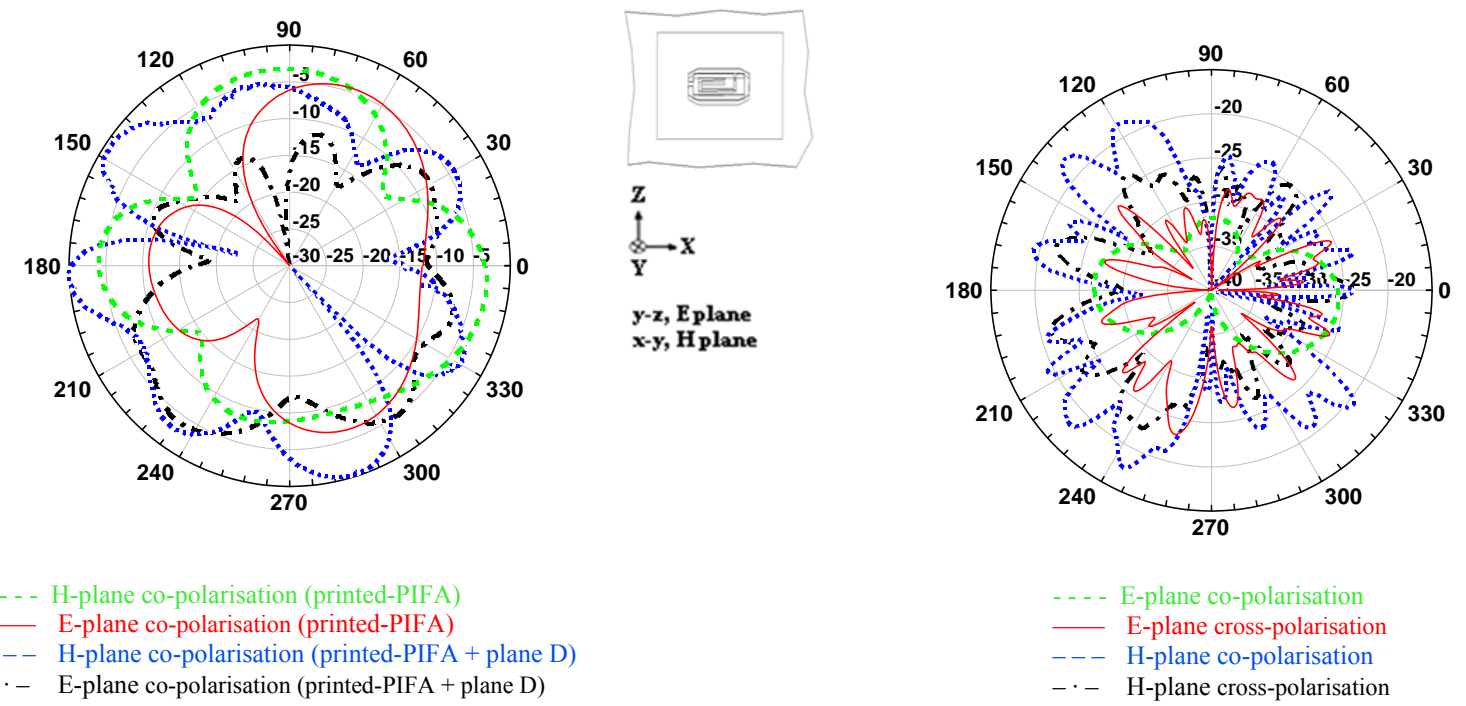

Figure 9 - Radiation pattern of the printed-PIFA with and without the extra ground plane $D$.

Figure 10 - Radiation pattern seen outside the fuselage of the vehicle (simulated) 
Final author version. This paper has been published in IET Microwaves, Antennas \& Propagation. Volume 6, Issue 15. Pp 1674 - 1680. 2012

\section{Tables}

$\begin{array}{lcccc}\begin{array}{c}\text { Element } \\ \text { I and } w\end{array} & \begin{array}{c}\text { Centered } \\ \text { frequency } \\ (\mathrm{MHz})\end{array} & \begin{array}{c}\text { Total } \\ \text { bandwidth } \\ (\%)\end{array} & \begin{array}{c}\text { Upper and } \\ \text { lower roll-offs } \\ (\mathrm{dB} / \mathrm{MHz})\end{array} & \begin{array}{c}\text { Reflection } \\ \text { coefficient } \\ (\mathrm{dB})\end{array} \\ +12 \mathrm{~mm} & 775.52 & 0.46 & 0.58 & -2 \\ +8 \mathrm{~mm} & 729.9 & 0.87 & 0.37 & -2 \\ +4 \mathrm{~mm} & 823 & 0.24 & 0.85 & -10 \\ \text { I and } w & 866.6 & 0.24 & 0.85 & -10 \\ -4 \mathrm{~mm} & 910.51 & 0.24 & 0.85 & -10 \\ -8 \mathrm{~mm} & 960.79 & 0.24 & 0.85 & -10 \\ -12 \mathrm{~mm} & 1010.13 & 0.24 & 0.85 & -10\end{array}$

Table 1 
Final author version. This paper has been published in IET Microwaves, Antennas \& Propagation. Volume 6, Issue 15. Pp 1674 - 1680. 2012

\begin{tabular}{|c|c|c|c|c|c|}
\hline $\begin{array}{c}\text { Thickness, } \\
\text { h (mm) }\end{array}$ & $\begin{array}{c}\text { Centre } \\
\text { Frequency } \\
\text { (MHz) }\end{array}$ & $\begin{array}{c}\text { Total } \\
\text { Bandwidth } \\
(\%)\end{array}$ & $\begin{array}{c}\text { Upper } \\
\text { and } \\
\text { lower } \\
\text { roll-offs } \\
\text { (db/MHz) }\end{array}$ & $\begin{array}{l}\text { Reflection } \\
\text { coefficient } \\
\text { (dB) }\end{array}$ & $\begin{array}{l}\text { Gain } \\
\text { (dBi) }\end{array}$ \\
\hline 3.8 & 839.76 & 0.4 & 0.09 & -2 & -3.1 \\
\hline 3.2 & 845.34 & 0.24 & 0.28 & -5 & -1.5 \\
\hline 2.6 & 852.79 & 0.16 & 0.66 & -10 & 2.5 \\
\hline 2.508 & 854.65 & 0.19 & 0.58 & -10 & 2.5 \\
\hline 2.381 & 856.52 & 0.2 & 0.52 & -10 & 2.5 \\
\hline 2.254 & 859.31 & 0.24 & 0.45 & -10 & 2.1 \\
\hline 2.127 & 862.10 & 0.24 & 0.39 & -10 & 2.8 \\
\hline 2 & 866.6 & 0.24 & 0.85 & -10 & 2.5 \\
\hline 1.873 & $\mathrm{n} / \mathrm{a}$ & short circuit & $\mathrm{n} / \mathrm{a}$ & $\mathrm{n} / \mathrm{a}$ & $\mathrm{n} / \mathrm{a}$ \\
\hline $\begin{array}{c}\text { Thickness, } \\
\text { h' }^{\prime}(\mathrm{mm})\end{array}$ & $\begin{array}{c}\text { Centre } \\
\text { Frequency } \\
\text { (MHz) }\end{array}$ & $\begin{array}{c}\text { Total } \\
\text { Bandwidth } \\
(\%)\end{array}$ & $\begin{array}{c}\text { Upper } \\
\text { and } \\
\text { lower } \\
\text { roll-offs } \\
\text { (db/MHz) }\end{array}$ & $\begin{array}{l}\text { Reflection } \\
\text { coefficient } \\
\text { (dB) }\end{array}$ & $\begin{array}{l}\text { Gain } \\
\text { (dBi) }\end{array}$ \\
\hline 4.054 & 895.62 & 0.33 & 0.16 & -10 & 3.5 \\
\hline 3.454 & 890.03 & 0.33 & 0.29 & -10 & 4.5 \\
\hline 2.854 & 882.58 & 0.31 & 0.36 & -10 & 4.2 \\
\hline 2.254 & 873.27 & 0.26 & 0.36 & -10 & 3.2 \\
\hline 2.127 & 870.48 & 0.26 & 0.41 & -10 & 3.3 \\
\hline 2 & 868.62 & 0.25 & 0.47 & -10 & 3.1 \\
\hline 1.873 & 866.6 & 0.24 & 0.85 & -10 & 2.5 \\
\hline 1.746 & 863.96 & 0.22 & 0.36 & -10 & 1 \\
\hline 1.619 & 861.17 & 0.21 & 0.41 & -10 & 1.2 \\
\hline 1.492 & 857.45 & 0.22 & 0.49 & -10 & 1.5 \\
\hline 0.892 & 839.76 & 0.33 & 0.22 & -5 & -2.7 \\
\hline 0.292 & $\mathrm{n} / \mathrm{a}$ & mismatch & $\mathrm{n} / \mathrm{a}$ & 0 & -32 \\
\hline
\end{tabular}

Table 2 
Final author version. This paper has been published in IET Microwaves, Antennas \& Propagation. Volume 6, Issue 15. Pp 1674 - 1680. 2012

\begin{tabular}{|c|c|c|c|c|c|c|c|c|c|}
\hline tag & $\mathrm{dBm}$ & tag & $\mathrm{dBm}$ & tag & $\mathrm{dBm}$ & tag & $\mathrm{dBm}$ & tag & $\mathrm{dBm}$ \\
\hline a & 29 & $\mathbf{a}^{1}$ & 29 & $\mathbf{a}^{2}$ & 20.9 & $a^{3}$ & 28.4 & $a^{4}$ & 15.8 \\
\hline b & 23 & $\mathbf{b}^{1}$ & 30 & $\mathbf{b}^{2}$ & 21.3 & $\mathbf{b}^{3}$ & 28.8 & $\mathbf{b}^{4}$ & 22.8 \\
\hline C & 29 & $c^{1}$ & 18 & $c^{2}$ & 29.8 & $c^{3}$ & 23.4 & $c^{4}$ & 30 \\
\hline d & 30 & $d^{1}$ & 23.9 & $d^{2}$ & 19.5 & $d^{3}$ & 25.7 & $d^{4}$ & 25.8 \\
\hline e & 28 & $\mathbf{e}^{1}$ & 29.3 & $\mathbf{e}^{2}$ & 29.3 & $\mathbf{e}^{3}$ & 30 & $e^{4}$ & 17.7 \\
\hline f & 25 & $\mathbf{f}^{1}$ & 30 & $\mathbf{f}^{2}$ & 30 & $\mathbf{f}^{3}$ & 30 & $\mathbf{f}^{4}$ & 25.7 \\
\hline g & 24 & $\mathrm{~g}^{1}$ & 26.2 & $\mathrm{~g}^{2}$ & 29 & $\mathrm{~g}^{3}$ & 26 & $\mathrm{~g}^{4}$ & 15.8 \\
\hline h & 28.8 & $\mathbf{h}^{1}$ & 24 & $\mathbf{h}^{2}$ & 24 & $\mathbf{h}^{3}$ & 23.6 & $\mathbf{h}^{4}$ & 30 \\
\hline $\mathbf{i}$ & 25 & $\mathbf{i}^{1}$ & 18.2 & $\mathbf{i}^{2}$ & 16 & $\mathbf{i}^{3}$ & 26 & $\mathbf{i}^{4}$ & 24.9 \\
\hline $\mathbf{j}$ & 30 & $\mathbf{j}^{1}$ & 28.5 & $\mathbf{j}^{2}$ & 25.3 & $\mathbf{j}^{3}$ & 29.5 & $\mathbf{j}^{4}$ & 28 \\
\hline $\mathbf{k}$ & 23.7 & $\mathbf{k}^{1}$ & 30 & $\mathbf{k}^{2}$ & 30 & $\mathbf{k}^{3}$ & 28.8 & $\mathbf{k}^{4}$ & 25.9 \\
\hline 1 & 23.5 & $\mathbf{l}^{1}$ & 27.3 & $\mathbf{l}^{2}$ & 28.6 & $\mathbf{l}^{3}$ & 26.2 & $1^{4}$ & 16.3 \\
\hline $\mathbf{m}$ & 28 & $\mathbf{m}^{1}$ & 23.3 & $\mathrm{~m}^{2}$ & 22.8 & $\mathbf{m}^{3}$ & 23 & $\mathrm{~m}^{4}$ & 30 \\
\hline n & 25 & $n^{1}$ & 19.8 & $\mathrm{n}^{2}$ & 15 & $\mathbf{n}^{3}$ & 27 & $n^{4}$ & 24.9 \\
\hline о & 29.5 & $\mathbf{0}^{1}$ & 28.2 & $\mathbf{0}^{2}$ & 26.8 & $\mathbf{0}^{3}$ & 30 & $\mathbf{0}^{4}$ & 28 \\
\hline $\mathbf{p}$ & 27.2 & $p^{1}$ & 29.8 & $\mathbf{p}^{2}$ & 22 & $\mathbf{p}^{3}$ & 29.5 & $\mathbf{p}^{4}$ & 17.8 \\
\hline $\mathbf{q}$ & 22.5 & $\mathbf{q}^{1}$ & 30 & $\mathbf{q}^{2}$ & 19.8 & $\mathbf{q}^{3}$ & 29 & $q^{4}$ & 24 \\
\hline $\mathbf{r}$ & 28.5 & $\mathbf{r}^{1}$ & 18 & $\mathbf{r}^{2}$ & 30 & $\mathbf{r}^{3}$ & 21.9 & $r^{4}$ & 30 \\
\hline $\mathbf{S}$ & 30 & $s^{1}$ & 23.5 & $\mathrm{~s}^{2}$ & $\begin{array}{l}19.7 \\
\end{array}$ & $\mathrm{~s}^{3}$ & 25 & $\mathrm{~s}^{4}$ & 25.8 \\
\hline$t$ & 26.5 & $t^{1}$ & 30 & $t^{2}$ & 28.9 & $\mathbf{t}^{3}$ & 30 & $\mathbf{t}^{4}$ & 15.9 \\
\hline $\mathbf{u}$ & 25.5 & $\mathbf{u}^{1}$ & 27.7 & $\mathbf{u}^{2}$ & 20.5 & $\mathbf{u}^{3}$ & 26 & $\mathbf{u}^{4}$ & 25.8 \\
\hline $\mathbf{v}$ & 30 & $\mathbf{v}^{1}$ & 21.3 & $\mathbf{v}^{2}$ & 28 & $\mathbf{v}^{3}$ & 24 & $\mathrm{v}^{4}$ & 30 \\
\hline $\mathbf{w}$ & 28.8 & $w^{1}$ & 28.9 & $w^{2}$ & 29.1 & $w^{3}$ & 29.8 & $w^{4}$ & 27.6 \\
\hline $\mathbf{x}$ & 27.7 & $\mathrm{x}^{1}$ & 30 & $\mathrm{x}^{2}$ & 30 & $\mathbf{x}^{3}$ & 30 & $x^{4}$ & 27.4 \\
\hline $\mathbf{y}$ & 25.4 & $y^{1}$ & 22.9 & $\mathbf{y}^{2}$ & 29.8 & $\mathbf{y}^{3}$ & 25.1 & $y^{4}$ & 24.7 \\
\hline
\end{tabular}

Table 3 